\title{
NIIN AS AN OHMIC CONTACT TO P-GAN
}

\author{
D. B. Ingerly*, Y. A. Chang* and Y. Chen** \\ *Department of Materials Science and Engineering, University of Wisconsin, Madison, \\ Wisconsin 53706-1595 \\ **Hewlett-Packard Company, 3500 Deer Creek Road, Palo Alto, California 94304-1392
}

\section{Cite this article as: MRS Internet J. Nitride Semicond. Res. 4S1, G6.49(1999)}

\begin{abstract}
ABSRTACT
Based on the criteria for the solid state exchange reaction with $\mathrm{p}-\mathrm{GaN}$, we have investigated the intermetallic compound NiIn as a possible ohmic contact. The contacts were fabricated by depositing NiIn on $\mathrm{p}-\mathrm{GaN}$ films $\left(\mathrm{p} \sim 2 \times 10^{17} \mathrm{~cm}^{-3}\right)$ using RF sputtering from a compound target. The as-deposited, NiIn contacts were found to be rectifying and using I-V characterization a Schottky barrier height of $0.82 \mathrm{eV}$ was measured. Rapid thermal annealing of the contacts was shown to significantly decrease their resistance, with contacts annealed at 800 ${ }^{\circ} \mathrm{C}$ for $1 \mathrm{~min}$ yielding the lowest resistance. When annealed at $800{ }^{\circ} \mathrm{C}$ for 1 min NiIn contacts exhibited a specific contact resistance of $8-9 \times 10^{-3} \Omega \mathrm{cm}^{2}$, as measured by the circular transmission line model. To allow a more universal comparison the more traditional $\mathrm{Ni} / \mathrm{Au}$ contacts, processed under the same conditions, were used as a standard. Their measured specific contact resistance $\left(\rho_{\mathrm{c}}=1.2-2.1 \times 10^{-2} \Omega \mathrm{cm}^{2}\right)$ was significantly higher than that of the NiIn contacts. Demonstrating that NiIn has promise as an ohmic contact to $\mathrm{p}-\mathrm{GaN}$ and should be studied in greater detail.
\end{abstract}

\section{INTRODUCTION}

It has long been realized that the III-V nitrides have tremendous potential for optoelectronic devices operating in the blue and UV wavelengths as well as for use in high power-high temperature semiconductor devices. The III-V nitrides form a continuous alloy system whose direct band gap ranges from $6.2 \mathrm{eV}(\mathrm{AlN})$ to $3.4 \mathrm{eV}(\mathrm{GaN})$ to $1.9 \mathrm{eV}(\mathrm{InN})$ at room temperature. ${ }^{1}$ This potentially allows the fabrication of high efficiency optical devices, such as Light Emitting Diodes (LEDs), which can operate from orange to the UV region. The extension into the green and blue wavelengths completes the visible spectrum allowing semiconductor technology to be used for applications such as large full color displays and traffic lights. $^{2,3}$

Early research into the nitrides outlined several problem areas, which hindered efforts to produce devices based on III-V nitride technology. Particularly the lack of p-GaN made the fabrication of efficient optical devices based on $\mathrm{p}$-n junctions impossible, though some LEDs based on metal-insulator-semiconductors were fabricated. ${ }^{1,3}$ Only recently due to advances in $\mathrm{p}$ type doping has $\mathrm{GaN}$ started to realize its potential and there are now nitride based devices available. However, the metal contact to $\mathrm{p}-\mathrm{GaN}$ is an important concern since high contact resistance will substantially reduce the performance of $\mathrm{GaN}$ based devices. In fact, the high resistance of the metal/p-GaN contact is one of the most significant issues limiting laser diode performance.

Most of the current work on finding low resistance metallizations to $\mathrm{p}-\mathrm{GaN}$ has focused on high work function elemental metals deposited in multilayer structures. ${ }^{4-11}$ This strategy is based on the Schottky model, which predicts that higher work function metals will result in lower Schottky barriers to p-type semiconductors. The limited experimental evidence available 
on metal/p-GaN contacts suggests that the Schottky model is at least partially applicable. ${ }^{4}$ Of the several contact schemes to $\mathrm{p}-\mathrm{GaN}$ that have been studied $\mathrm{Au} / \mathrm{Ni}$ contacts have received the most attention. Despite being used in devices, the $\mathrm{Au} / \mathrm{Ni}$ contacts typically exhibit a specific contact resistance $\left(\rho_{c}\right)$ in the range of $10^{-3}$ and $10^{-2} \Omega \mathrm{cm}^{2}$ range $e^{7,8,12}$ and show poor thermal stability. ${ }^{13}$ However, it is known that the specific contact resistance of $\mathrm{p}-\mathrm{GaN}$ depends on many factors such as the quality of the bulk substrate and its surface preparation and processing conditions. Accordingly, it is difficult to judge the absolute resistance values reported.

In an attempt to find new metallizations that can be used to form ohmic contacts to p$\mathrm{GaN}$ the solid-state exchange reaction was utilized. This reaction has been shown to be a systematic approach for tailoring metal/semiconductor contact properties. ${ }^{14-17}$ The complete thermodynamic and kinetic model for the exchange mechanism has been comprehensively set forth by Swenson et al. ${ }^{18}$ Based on the exchange mechanism criteria, the intermetallic compound NiIn was selected as possible ohmic contact to $\mathrm{p}-\mathrm{GaN}$.

The thermodynamically stable phase of NiIn (50:50 at \% ratio) has a CoSn (B35) crystal structure, however, the metastable B2 phase often forms and is the structure of the NiIn films used in this study. This B2 phase is thermodynamically stable at high temperature in Ni-In alloys that have 51 to $58 \%$ In. $^{19}$

\section{EXPERIMENTAL PROCEDURE}

The GaN substrates used in this study are $1.2 \mu \mathrm{m}$ thin films of single crystal GaN grown by metalorganic vapor phase epitaxy (MOVPE) on sapphire (0001). The GaN epilayer is $\mathrm{Mg}$ doped and was annealed to activate the dopants. A p-type carrier concentration of $2 \times 10^{17} \mathrm{~cm}^{-3}$ with a mobility of $8 \mathrm{~cm} / \mathrm{V}$ s was measured by Hall probe at room temperature. Prior to lithography, the substrates were ultrasonically degreased with Acetone and Methanol for $10 \mathrm{~min}$ each. These degreased substrates were then etched in $\mathrm{HCl}: \mathrm{H}_{2} \mathrm{O}(1: 2)$ for 4 min and then rinsed in flowing $\mathrm{H}_{2} \mathrm{O}$ for 10 min.

Using standard photolithography techniques the substrates were patterned with a circular transmission line model (TLM) pattern similar to the one detailed by Marlow. ${ }^{20}$ Schottky barrier heights were measured by Current-Voltage (I-V) characteristics using the $140 \mu \mathrm{m}$ diameter pad as the diode and the large area metallization as the ohmic contact. The specific contact resistance $\left(\rho_{c}\right)$ measurements were conducted at 5 volts using the circular TLM pattern which consists of 7 different contact pads with gap spacing ranging from 4 to $25 \mu \mathrm{m}$. Once patterned, the substrates were then placed in a $\mathrm{HCl}: \mathrm{H}_{2} \mathrm{O}(1: 4)$ solution for 20 seconds, blown dry with Nitrogen gas and immediately loaded into a vacuum chamber with the background pressure less than $2 \times 10^{-7}$ torr.

The NiIn (50:50 at \% ratio) was deposited by sputtering from a compound target to a nominal $80 \mathrm{~nm}$ thickness. The annealed NiIn films were found by X-ray diffraction to be in the metastable B2 crystal structure when deposited by RF sputtering under the conditions used. As a control standard, Ni/Au contacts were also fabricated. These films were deposited by e-beam evaporation, with $\mathrm{Ni}$ and $\mathrm{Au}$ film thickness of 20 and $100 \mathrm{~nm}$, respectively.

After deposition, the photoresist was lifted off in an acetone bath leaving the patterned metal on the wafers. Following liftoff, the contacts were annealed in an AG Associated MiniPulse rapid thermal annealing (RTA) system with flowing high purity Nitrogen gas. The electrical properties of the contacts were measured with a Keithley Model 236 electrometer employed as a current source and voltage meter. 


\section{ELECTRICAL RESULTS}

As discussed in the introduction, the intermetallic compound NiIn has been selected for study as an ohmic contact to p-GaN. However, it is difficult to compare the specific contact resistance for different metallizations reported by different researchers due to the wide variability in $\mathrm{p}-\mathrm{GaN}$ substrates because these substrate differences can play an important role in the measured properties of the contacts. Therefore, in order to allow a more universal comparison of the NiIn metallization evaluated in this study we have used Ni/Au contacts as a standard.

All of the as-deposited contacts exhibited highly rectifying behavior; and it was decided that the Schottky barrier height is a more appropriate measure of these contacts' electrical behavior than the $\rho_{c}$ at a given voltage. By evaluating the I-V behavior at small voltages the Schottky barrier and ideality factor can be determined by fitting the data to the following equation:

$$
I=A^{*} S T^{2} e^{\left(-q \phi_{b} / k T\right)}\left(e^{q V / n k T}-1\right)
$$

where $\mathrm{A}^{*}$ is the Richardson constant, $\mathrm{S}$ is the diode area, $\mathrm{T}$ is the temperature, $\mathrm{q}$ is the electron charge, $\phi_{\mathrm{b}}$ is the Schottky barrier height, $\mathrm{k}$ is the Boltzman constant, $\mathrm{V}$ is the applied voltage and $\mathrm{n}$ is the ideality factor. ${ }^{21}$ Schottky barrier heights determined for the contacts in the as-deposited state are listed in Table 1. To the best of our knowledge, a value for NiIn on p-GaN has not been previously reported. However, the $0.77 \mathrm{eV}$ value of the Schottky barrier height of Ni/p-GaN determined in this study is significantly higher than the $0.5 \mathrm{eV}$ value reported by Mori, et al. ${ }^{4}$ While the reason for such a discrepancy is not known, Ishikawa, et $\mathrm{al}^{22}$ reported about the difficulty in measuring the barrier height of metals on p-GaN. Additionally the ideality factors for all of the contacts measured were significantly greater than 1; showing that the carrier transport mechanism is not entirely due to thermionic emission and suggesting that the interface is not uniform. ${ }^{23}$ For the Schottky barrier measurement an ohmic contact is required in addition to the Schottky diode. In this study, the ohmic contact was approximated using a large area contact of the same metallization and while this contact is many times larger than the diode, it is not a true ohmic contact. Given the difficulties of measuring the barrier height of metals on $\mathrm{p}$ $\mathrm{GaN}$ and the large ideality factors, the absolute value of barrier heights reported in this study should be interpreted accordingly.

Table 1. Ideality factors and Schottky barrier height for as-deposited contacts

\begin{tabular}{|c|c|c|}
\hline Metallization & Ideality Factor $(\mathrm{n})$ & Schottky Barrier Height \\
\hline $\mathrm{NiIn}$ & 1.22 & $0.82 \mathrm{eV}$ \\
\hline $\mathrm{Ni} / \mathrm{Au}$ & 1.16 & $0.77 \mathrm{eV}$ \\
\hline
\end{tabular}

With increased annealing temperature the resistance of the $\mathrm{NiIn} / \mathrm{p}-\mathrm{GaN}$ contacts decreased. The lowest contact resistance occurs after annealing at $800{ }^{\circ} \mathrm{C}$ for $1 \mathrm{~min}$, contacts subjected to a higher annealing temperature, $850{ }^{\circ} \mathrm{C}$ for $1 \mathrm{~min}$ or increased annealing time, 800 ${ }^{\circ} \mathrm{C}$ for 5 min showed a higher resistance than the samples annealed at $800^{\circ} \mathrm{C}$ for $1 \mathrm{~min}$. Table 2 gives the specific contact resistance on NiIn/p-GaN contacts at three different annealing conditions. One possibility for the increased resistances at more severe annealing conditions is oxidation of the NiIn layer. Scanning Auger Microscopy showed that significant oxidation occurred from the surface into over half of the NiIn film for contacts annealed at $800{ }^{\circ} \mathrm{C}$ for 1 min. It is possible that once a significant level of oxidation is reached at the metal/semiconductor interface the contact resistance will increase. 
Table 2. Specific Contact Resistance for NiIn contacts

\begin{tabular}{|c|c|}
\hline Annealing Conditions & Specific Contact Resistance \\
\hline $750{ }^{\circ} \mathrm{C}$ for $1 \mathrm{~min}$ & $6.2 \times 10^{-2} \Omega \mathrm{cm}^{2}$ \\
\hline $800^{\circ} \mathrm{C}$ for $1 \mathrm{~min}$ & $9.5 \times 10^{-3} \Omega \mathrm{cm}^{2}$ \\
\hline $800^{\circ} \mathrm{C}$ for $5 \mathrm{~min}$ & $7.4 \times 10^{-2} \Omega \mathrm{cm}^{2}$ \\
\hline
\end{tabular}

Due to the wide variability in $\mathrm{p}-\mathrm{GaN}$ films and the direct role the films have in the measured specific contact resistance we have used $\mathrm{Ni} / \mathrm{Au}$ contacts to $\mathrm{p}-\mathrm{GaN}$ as a standard. Table 3 shows a comparison of NiIn contacts annealed at $800{ }^{\circ} \mathrm{C}$ for $1 \mathrm{~min}$ to $\mathrm{Ni} / \mathrm{Au}$ annealed at $750{ }^{\circ} \mathrm{C}$ for $1 \mathrm{~min}$. These contacts were subject to the same processing conditions and the annealing conditions used represent the optimum conditions found in this study for the two different metallizations. For both p-GaN substrates used, the NiIn contacts had a lower measured specific contact resistance than the Ni/Au contacts. Figures 1(a) and 1(b) show the I-V behavior of the annealed NiIn and Ni/Au contacts, respectively. These curves were measured on back-to-back $140 \mu \mathrm{m}$ in diameter contacts. Figures 1(a) and 1(b) clearly show that these contacts do not exhibit true ohmic behavior.

Table 3. A comparison of specific contact resistance NiIn Vs. Ni/Au

\begin{tabular}{|c|c|c|}
\hline Substrate & NiIn $\left(800{ }^{\circ} \mathrm{C}\right.$ for $\left.1 \mathrm{~min}\right)$ & $\mathrm{Ni} / \mathrm{Au}\left(750^{\circ} \mathrm{C}\right.$ for $\left.1 \mathrm{~min}\right)$ \\
\hline 1 & $8.0 \times 10^{-3} \Omega \mathrm{cm}^{2}$ & $1.2 \times 10^{-2} \Omega \mathrm{cm}^{2}$ \\
\hline 2 & $9.5 \times 10^{-3} \Omega \mathrm{cm}^{2}$ & $2.1 \times 10^{-2} \Omega \mathrm{cm}^{2}$ \\
\hline
\end{tabular}

These electrical results show that NiIn has potential as an ohmic contact to p-GaN. However to understand the NiIn/p-GaN contacts, particularly its large resistance change upon annealing, will require careful interfacial characterization. At this time it is not clear what mechanism is responsible for the change in contact resistance due to annealing and the role oxidation may play in the measured resistance is equally unknown. It is this type of information, which is required not only to increase our understanding but also aid in the optimization of the NiIn contacts.

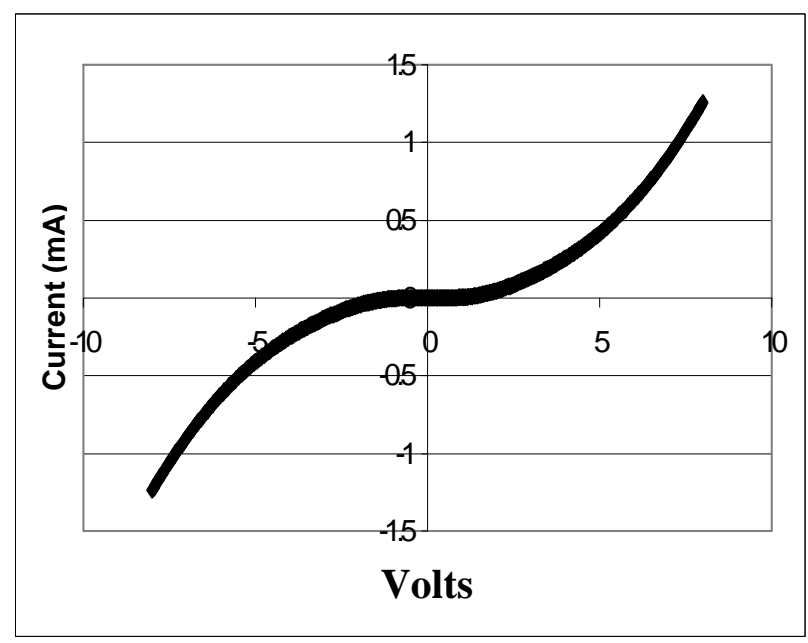

Figure 1(a) I-V behavior of NiIn/p-GaN contacts annealed at $800^{\circ} \mathrm{C}$ for $1 \mathrm{~min}$.

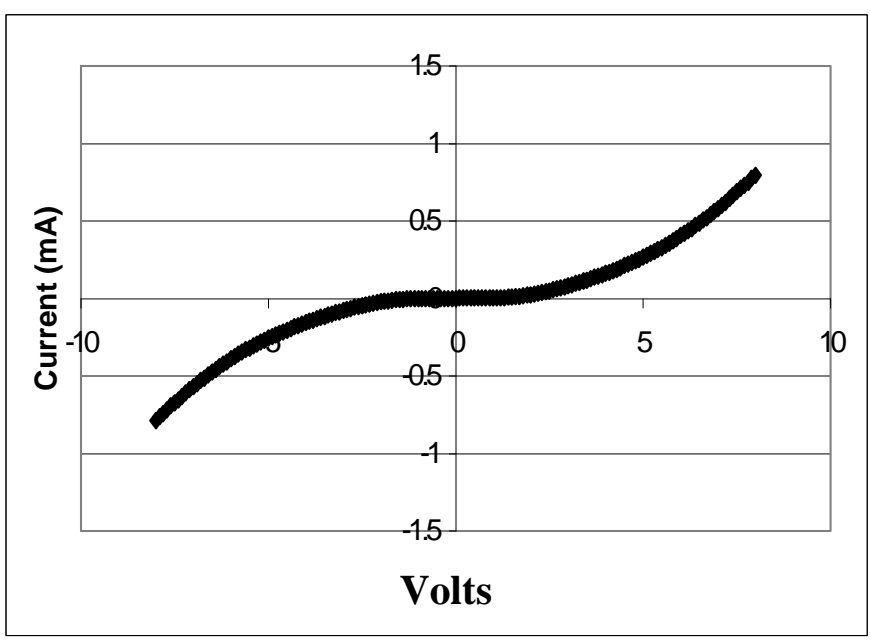

Figure 1(b) I-V behavior of NiIn/p-GaN contacts annealed at $750{ }^{\circ} \mathrm{C}$ for $1 \mathrm{~min}$. 


\section{CONCLUSIONS}

The intermetallic compound NiIn (50:50 at \% ratio) was selected based on the criteria for the exchange mechanism as possible ohmic contacts to $\mathrm{p}-\mathrm{GaN}$. Contacts were fabricated on $\mathrm{p}$ $\mathrm{GaN}$ films using RF sputtering from a compound target. In the as-deposited state these contacts were found to be rectifying and using I-V characterization a Schottky barrier height $0.82 \mathrm{eV}$ was determined for the contact. Rapid thermal annealing of the NiIn contacts was shown to decrease their resistance with increasing annealing temperature. Contacts annealed at $800{ }^{\circ} \mathrm{C}$ for $1 \mathrm{~min}$ had the lowest resistance of the annealing conditions examined in this study. At this annealing condition the specific contact resistance of the NiIn contacts was measured to be $8-9 \times 10^{-3}$ $\Omega \mathrm{cm}^{2}$ using the circular TLM method. Annealing at higher temperatures or longer times resulted in an increase in specific contact resistance. It is speculated based upon Auger depth profiling that oxidation maybe responsible for this resistance increase at annealing conditions more severe than $800{ }^{\circ} \mathrm{C}$ for $1 \mathrm{~min}$. The measured electrical properties of NiIn are promising since the specific contact resistance of NiIn is lower than the more traditionally used $\mathrm{Ni} / \mathrm{Au}$ contact $\left(\rho_{c}=1.2-2.1 \times 10^{-2} \Omega \mathrm{cm}^{2}\right)$ processed under the same conditions.

\section{ACKNOWLEDGEMENTS}

The authors would like to thank Rick Schneider at the Hewlett-Packard Company for providing the $\mathrm{p}-\mathrm{GaN}$ films used in this study and the National Science Foundation for its support of this project through grant number NSF-DMR-94-24478.

\section{REFERENCES}

1. H. Morkoc, S. Strite, G. B. Gao, M. E. Lin, B. Sverdlov, and M. Burns, J. Appl. Phys. 76(3), 1363 (1994).

2. H. Morkoc and S. N. Mohammad, Science 267, 51 (1995).

3. S. J. Pearton and C. Kuo, MRS Bulletin 22, 17 (1997).

4. T. Mori, T. Kozawa, T. Ohwaki, Y. Taga, S. Nagai, S. Yamasaki, S. Asami, N. Shibata and M. Koike, Appl. Phys. Lett. 69(23), 3537 (1996).

5. S. Nakamura, M. Senoh, N. Iwasa and S. Nagahama, Jpn. J. Appl. Phys. 34, L797 (1995).

6. J. T. Trexler, S, J Miller, P. H. Holloway and M. A. Khan, Mater. Res. Soc. Sympo. Proc. 395, 819 (1996).

7. T. Kim, M. C. Yoo, and T. Kim, Mater. Res. Soc. Symp. Proc. 449, 1061 (1997).

8. D. J. King, L. Zhang, J. C. Ramer, S. D. Hersee, L. F. Lester, Mater. Res. Soc. Symp. Proc. 468, 421 (1997).

9. L. L. Smith, R. F. Davis, M. J. Kim, R. W. Carpenter and Y. Huang, J. Mater. Res. 12, 2249 (1997).

10. J. T. Trexler, S. J. Pearton, P. H. Holloway, M. G. Mier, K. R. Evans, and R. F. Karlicek, Mater. Res. Soc. Symp. Proc. 449, 1091 (1997).

11. J. -S. Soon, H. -G. Kim, K. -H. Park, C. -S. Um, I. -L. Han, S. -H. Kim, H. -K. Jang, S. -J. Park, Mater. Res. Soc. Symp. Proc. 482, 1053 (1998).

12. S. Nakamura, Mater. Res. Soc. Symp. Proc. 482, 1145 (1998).

13. H.S. Venugopalan, S.E. Mohney, B. P. Luther, J. M. DeLucca, S. D. Wolter, J. M. Redwing, and G. E. Bulman, Mater. Res. Soc. Symp. Proc. 468, 431 (1997).

14. C.-F. Lin, Y. A. Chang, N. Pan, J.-W. Huang, and T.-F. Kuech, Appl. Phys. Lett. 67, 3587 (1995). 
15. D. Y. Chen, Y. A. Chang and D. Swenson, Appl. Phys. Lett. 68, 96 (1996).

16. D.Y.Chen, Y. A. Chang and D. Swenson, J. Appl. Phys. 81, 297 (1997).

17. D. Y. Chen, Ph. D. Thesis, University of Wisconsin, Madison, WI (1997).

18. D. Swenson, C. -H. Jan, Y. A. Chang, J. Appl. Phys. 84, (1998).

19. H. Okamoto, in T. B. Massalski (ed.), Binary Alloy Phase Diagrams, ASM International, Materials Park, OH, 2276 (1990) 2nd edn.

20. G. S. Marlow and M. B. Das, Solid-State Electronics 25, 91 (1982)

21. D. K. Schroder, Semiconductor Material and Device Characterization, John Wiley and Sons, Inc, New York, NY, 151 (1990)

22. H. Ishikawa, S. Kobayashi, Y. Koide, S. Yamasaki, S. Nagai, J. Umezaki, M. Koike, and M. Murakami, J. Appl. Phys. 81(3), 1315 (1997).

23. R.T. Tung, J. Vac. Sci. Technol. B 11(4), 1546 (1993). 